\title{
Article \\ Synthesis of Air-Stable Cu Nanoparticles Using Laser Reduction in Liquid
}

\author{
Ashish Nag (D), Laysa Mariela Frias Batista and Katharine Moore Tibbetts *(D) \\ Department of Chemistry, Virginia Commonwealth University, Richmond, VA 23284, USA; \\ nagab@vcu.edu (A.N.); friasbatistlm@vcu.edu (L.M.F.B.) \\ * Correspondence: kmtibbetts@vcu.edu
}

check for updates

Citation: Nag, A.; Frias Batista, L.M.; Tibbetts, K.M. Synthesis of Air-Stable $\mathrm{Cu}$ Nanoparticles Using Femtosecond Laser Reduction in Liquid. Nanomaterials 2021, 11, 814. https:// doi.org/10.3390/nano11030814

Academic Editor: Mohamed Boutinguiza

Received: 15 March 2021

Accepted: 21 March 2021

Published: 23 March 2021

Publisher's Note: MDPI stays neutral with regard to jurisdictional claims in published maps and institutional affiliations.

Copyright: (C) 2021 by the authors Licensee MDPI, Basel, Switzerland. This article is an open access article distributed under the terms and conditions of the Creative Commons Attribution (CC BY) license (https:/ / creativecommons.org/licenses/by/ $4.0 /)$.

\begin{abstract}
We report the synthesis of air-stable Cu nanoparticles (NPs) using the bottom-up laser reduction in liquid method. Precursor solutions of copper acetlyacetonate in a mixture of methanol and isopropyl alcohol were irradiated with femtosecond laser pulses to produce $\mathrm{Cu}$ NPs. The $\mathrm{Cu}$ NPs were left at ambient conditions and analyzed at different ages up to seven days. TEM analysis indicates a broad size distribution of spherical NPs surrounded by a carbon matrix, with the majority of the NPs less than $10 \mathrm{~nm}$ and small numbers of large particles up to $\sim 100 \mathrm{~nm}$ in diameter. XRD collected over seven days confirmed the presence of fcc-Cu NPs, with some amorphous $\mathrm{Cu}_{2} \mathrm{O}$, indicating the stability of the zero-valent $\mathrm{Cu}$ phase. Raman, FTIR, and XPS data for oxygen and carbon regions put together indicated the presence of a graphite oxide-like carbon matrix with oxygen functional groups that developed within the first $24 \mathrm{~h}$ after synthesis. The $\mathrm{Cu}$ NPs were highly active towards the model catalytic reaction of para-nitrophenol reduction in the presence of $\mathrm{NaBH}_{4}$.
\end{abstract}

Keywords: laser synthesis; laser reduction in liquid; copper nanoparticles; para-nitrophenol

\section{Introduction}

Laser synthesis techniques have emerged over the last decade as reliable methods for producing pure nanomaterials (NMs) [1-3]. Laser synthesis has several advantages over traditional chemical synthesis methods including: facile generation of metastable phases and bonding environments, rapid conversion of precursors to NM products, and avoidance of capping ligands. For instance, alloys of immiscible metals can be formed [4], reactions can be completed in seconds [5], and grams per hour synthesis yields can be attained with high-repetition rate lasers [6]. Moreover, laser synthesis techniques are considered 'green' because they do not employ toxic chemical reducing agents or surfactants and produce little chemical waste [7].

The lack of otherwise required capping ligands results in high purity nanoparticles that are important to several applications. Biofunctional assemblies can be produced by functionalizing laser-generated nanoparticles (NPs) for in-vitro applications [8]. The absence of ligands makes more active sites available for catalysis, resulting in laser-synthesized NPs often having higher activities than their conventional counterparts [9-11]. Higher purity also makes laser-synthesized NPs attractive candidates for other biomedical applications and as references for modeling chemical reactions [12-15]. In addition, photoluminescence can be introduced to the NPs by in-situ generation of carbon shells through laser-induced decomposition of organic solvents [16,17].

$\mathrm{Cu}$ NPs in particular are of high interest both due to the natural abundance of copper and their myriad applications in catalysis, electronics, and biology [18-22]. However, conventional wet-chemical methods used to synthesize $\mathrm{Cu}$-based NPs require toxic solvents, reducing agents, or both [23-25]. Hence, greener synthesis routes to Cu NPs are of primary importance. To address this need, pulsed laser ablation in liquid (PLAL) has been widely employed to generate $\mathrm{Cu}$ NPs [26-30]. In these syntheses, copper oxides are a major product when ablation is conducted in water [26-29], and $\mathrm{Cu}^{0}$ phases are only 
stable when the ablation liquid contains an organic solvent, such as acetone, methanol, or ethanol [28-30].

The top-down PLAL method is by far the most common laser synthesis technique used to produce colloidal metal NPs [1]. PLAL involves focusing of laser beam on the surface of a solid or powdered target immersed in a solvent, causing the removal of target material from the surface and its coalescence into colloidal NPs. However, NP products from PLAL in many cases exhibit bimodal size distributions due to the ejection of both small clusters and large droplets from the surface [31-33]. An alternative method is bottom-up laser reduction in liquid (LRL), which involves focusing picosecond (ps, $10^{-12} \mathrm{~s}$ ) or femtosecond ( $\mathrm{fs}, 10^{-15} \mathrm{~s}$ ) laser pulses into a solution of molecular precursors to generate a dense plasma containing electrons that reduce metal ions to colloidal NPs. LRL can enable superior control over Au NP sizes in a single step when the chemistry of the precursor solution and laser irradiation conditions are carefully controlled [34,35].

A current limitation to the wide use of LRL is that the vast majority of studies reported to date focus on the easily reduced noble metals Au [34-38], Ag [39-41], Pt [42], and their alloys [43-45] because these metals are resistant to oxidation. Unlike in PLAL where the zero-valent metal is present in the initial target, metal NP formation in LRL requires chemical reactions between the molecular precursor(s) and the reactive species in LRL plasma. In aqueous solution, the major species are hydrated electrons $\left(\mathrm{e}_{\mathrm{aq}}{ }^{-}\right)$and hydroxyl radicals $(\mathrm{OH} \cdot)$ [38]. Whereas $\mathrm{e}_{\mathrm{aq}}{ }^{-}$are exceptionally strong reducing agents towards metal ions, $\mathrm{OH} \cdot$ radicals and their recombination product $\mathrm{H}_{2} \mathrm{O}_{2}$ can back-oxidize zero-valent metal atoms. Although $\mathrm{Au}$ is resistant to back-oxidation and $\mathrm{HAuCl}_{4}$ precursor can be reduced by $\mathrm{H}_{2} \mathrm{O}_{2}$ [37], effective production of Ag-containing NPs by LRL requires the addition of $\mathrm{OH}$. scavengers, such as ammonia or isopropyl alcohol, to prevent backoxidation of $\mathrm{Ag}[40,41,45]$. Moreover, the few LRL studies on the non-noble metal Fe report production of only Fe oxides [46,47].

The detrimental effects of reactive oxygen species on $\mathrm{Cu}$ NP synthesis have been widely known since Dhas et al. [48] reported that $\mathrm{OH}$ - and $\mathrm{H}_{2} \mathrm{O}_{2}$ formed during sonochemical synthesis lead to the formation of copper oxides. In PLAL of $\mathrm{Cu}$ metal in water, $\mathrm{Cu}$ oxides are formed due to the presence of $\mathrm{OH}$ - radicals in the laser plasma from water, dissolved $\mathrm{O}_{2}$, or both [28]. Oxide formation during PLAL can be hindered through the use of organic solvents [27-30], which also can result in the formation of a protective carbon shell around the $\mathrm{Cu}$ NPs $[27,28]$. On the basis of these results, we designed an air-free LRL synthesis route to $\mathrm{Cu}$ NPs using an isopropyl alcohol/methanol solvent mixture. We report, to the best of our knowledge, the first LRL synthesis of air-stable Cu NPs and their catalytic activity towards reduction of para-nitrophenol in the presence of $\mathrm{NaBH}_{4}$.

\section{Materials and Methods}

\subsection{Materials}

Copper acetylacetonate $\left(\mathrm{Cu}(\mathrm{acac})_{2}\right.$, Acros Organics, Fair Lawn, NJ, USA), isopropyl alcohol (IPA, Fisher Scientific, Waltham, MA, USA), methanol (MeOH, Fisher Scientific, Waltham, MA, USA), sodium borohydride ( $\mathrm{NaBH}_{4}$, Acros Organics, Fair Lawn, NJ, USA), and para-nitrophenol (PNP, Acros Organics, Fair Lawn, NJ, USA) were used as received.

\section{2. $\mathrm{Cu} N P$ synthesis}

A working solution of $0.8 \mathrm{mM} \mathrm{Cu}(\mathrm{acac})_{2}$ in $25 \% / 75 \%(v / v) \mathrm{MeOH} / \mathrm{IPA}$ solvent was purged with nitrogen for $20 \mathrm{~min}$ before $3.0 \mathrm{~mL}$ of the solution was transferred to a nitrogenfilled $10 \times 10 \times 40 \mathrm{~mm}$ quartz fluorimeter cuvette. The solution was then irradiated with laser pulses to yield $\mathrm{Cu}$ NPs. Upon formation, $\mathrm{Cu}$ NPs were exposed to air and analyzed at different time intervals $(0 \mathrm{~h}, 3 \mathrm{~h}, 24 \mathrm{~h}$, and 7 days $)$ to study the aging of NPs. By $24 \mathrm{~h}$ after synthesis, all the $\mathrm{Cu}$ NPs are precipitated out of the solution but can be redispersed via brief sonication. 


\subsection{Instrumentation}

\subsubsection{Laser Synthesis}

The experimental setup is described elsewhere [38]. Briefly, samples were irradiated using a commercial titanium-sapphire chirped-pulse amplifier (Astrella, Coherent, Inc., Santa Clara, CA, USA), delivering $30 \mathrm{fs}$ pulses, with the bandwidth centered at $800 \mathrm{~nm}$ and a repetition rate of $1 \mathrm{kHz} ; 2 \mathrm{~mJ}$ laser pulses were focused using a $f=5 \mathrm{~cm}$ aspheric lens into the center of the sample cuvette to produce a peak irradiance of $5 \times 10^{16} \mathrm{Wcm}^{-2}$. Details for calculating peak irradiance can be found in Ref. [38]. The sealed cuvettes containing $\mathrm{Cu}(\mathrm{acac})_{2}$ solution were irradiated for $10 \mathrm{~min}$.

\subsubsection{UV-Vis Spectroscopy}

Conversion of precursors to $\mathrm{Cu}$ NPs was monitored using a home-built in-situ UV-vis spectrophotometer described in Ref. [38] and the irradiation was stopped when no further growth in $\mathrm{Cu}$ surface plasmon resonance (SPR) was observed. The catalytic performance of $\mathrm{Cu}$ NPs was tested for the reduction of PNP with $\mathrm{NaBH}_{4}$ (see Section 2.4) by employing a second home-built in-situ UV-vis spectrophotometer described in Ref. [49]. Finally, to observe the effect of aging of $\mathrm{Cu}$ NPs, absorbance data was recorded using Agilent 8453 UV-vis spectrophotometer at times up to 7 days after synthesis.

\subsubsection{Transmission Electron Microscopy (TEM)}

$\mathrm{Cu}$ NPs were visualized using TEM (JEOL JEM-1230 TEM) at $120 \mathrm{kV}$. A diluted solution of colloidal $\mathrm{Cu}$ NPs was drop-casted onto carbon-coated grids (Structure Probe, Inc., West Chester, PA, USA) and left to dry for $24 \mathrm{~h}$ or longer. Average sizes and size distributions were measured using ImageJ software. At least 350 particles from images of three separate areas of a TEM grid were evaluated.

\subsubsection{X-ray Photoelectron Spectroscopy (XPS)}

XP spectra were collected on a PHI VersaProbe III Scanning XPS Microprobe with a monochromated $\mathrm{Al} \mathrm{K} \alpha$ X-ray source $(1486.6 \mathrm{eV})$, with a typical resolution of $0.4-0.5 \mathrm{eV}$. Survey scans and high resolution scans were collected with pass energies of $280 \mathrm{eV}$ and 26 $\mathrm{eV}$, respectively. Charge neutralization was done by running an ion gun and a flood gun during sample analysis. The measurement spot diameter was $200 \mu \mathrm{m}$ with take off angle of $90^{\circ}$ and the detector at $45^{\circ}$. Spectral analysis was carried out using PHI Multipak XPS software with $70 \%$ Gaussian/Lorentzian convolution to fit each spectral peak. Samples were prepared by drop-casting $\mathrm{Cu}$ NPs on a gold-sputtered silicon wafer, followed by drying under vacuum for at least $24 \mathrm{~h}$. All spectra were corrected using a Au4f peak shift to center at $84.0 \mathrm{eV}$.

\subsubsection{FTIR Spectroscopy}

A Thermo Scientific Nicolet iS50 FTIR spectrometer equipped with a mid- and far-IRcapable diamond ATR was used to record FTIR spectra. All spectra were obtained using 32 scans in the range from 4000 to $400 \mathrm{~cm}^{-1}$ with $4 \mathrm{~cm}^{-1}$ resolution. Cu NPs were directly drop-casted on to the diamond crystal.

\subsubsection{X-ray Diffraction (XRD)}

XRD data was collected on a Panalytical Empyrean Diffractometer with $\mathrm{CuK} \alpha$ radiation $(0.15418 \mathrm{~nm})$ at $40 \mathrm{kV}$ and $45 \mathrm{~mA}$, with scanning angle $(2 \theta)$ of $30-80^{\circ}$ and a gonio focusing geometry. Sample preparation involved drop-casting of $\mathrm{Cu}$ NPs on a low-background silicon substrate, followed by drying under vacuum for at least $24 \mathrm{~h}$.

\subsubsection{Raman Spectroscopy}

Raman spectra were recorded on a Thermo Scientific DXR3 SmartRaman Spectrometer involving a $532 \mathrm{~nm}$ excitation laser. All spectra obtained were averaged over 32 scans in the 
range of 50 to $3500 \mathrm{~cm}^{-1}$ with $5 \mathrm{~cm}^{-1}$ resolution. Samples were prepared by drop-casting $\mathrm{Cu}$ NPs on a silicon wafer, followed by drying under vacuum for at least $24 \mathrm{~h}$.

\subsection{Catalytic Reduction of Para-Nitrophenol (PNP)}

PNP reduction reactions were carried out in a home-built in situ UV-vis spectrometer setup described elsewhere [35] at different time intervals after laser synthesis $(0 \mathrm{~h}, 3 \mathrm{~h}$, $24 \mathrm{~h}$, and 7 days). Spectra were recorded every $2.4 \mathrm{~s}$ using LabVIEW software (National Instruments). A solution containing a final concentration of $0.1 \mathrm{mM}$ PNP and $10 \mathrm{mM}$ of freshly prepared $\mathrm{NaBH}_{4}$ was prepared in a $10 \times 10 \times 40 \mathrm{~mm}$ quartz fluorimeter cuvette with a magnetic stir bar, resulting in the formation of $p$-nitrophenolate ion with UV-vis absorbance at $400 \mathrm{~nm}$. Prior to the addition of the catalyst, this peak was observed for $24 \mathrm{~s}$ to confirm no reaction occurred in the absence of a catalyst. After this period, $300 \mu \mathrm{L}$ of the $\mathrm{Cu}$ NP catalyst was added, triggering the reduction of PNP. Data collection was terminated when the absorbance at $400 \mathrm{~nm}$ ( $p$-nitrophenolate ion) had disappeared.

\section{Results}

\subsection{Physical Characterization}

Figure 1 shows TEM images and size distributions for $\mathrm{Cu}$ NPs samples obtained $0 \mathrm{~h}$ (a), $3 \mathrm{~h}$ (b), and $24 \mathrm{~h}$ (c) after laser synthesis. In all images, small $<10 \mathrm{~nm}$ NPs surrounding significantly larger NPs are observed. Fitting the size distributions to a log-normal function primarily captured the small NPs, producing mean diameters of $3.30 \mathrm{~nm}(\mathrm{PDI}=0.16)$, $4.54 \mathrm{~nm}(\mathrm{PDI}=0.19)$, and $4.57 \mathrm{~nm}(\mathrm{PDI}=0.16)$ for $0 \mathrm{~h}, 3 \mathrm{~h}$, and $24 \mathrm{~h}$ samples, respectively. Despite the large numbers of small NPs, they make up a tiny fraction of the overall mass of $\mathrm{Cu} \mathrm{NPs}$, as evident in the mass-weighted size distributions. Nevertheless, the contribution of NPs smaller than $10 \mathrm{~nm}$ to the overall mass slightly increased from $0.16 \%$ at $0 \mathrm{~h}$ to $0.34 \%$ at $3 \mathrm{~h}$ and $24 \mathrm{~h}$. The slight size increase in the small NPs after the initial synthesis was also observed for Fe oxide NPs synthesized by LRL from Fe(acac) ${ }_{3}$ in hexane [47], although, in that work, no large NPs were observed. A carbon shell around clusters of $\mathrm{Cu}$ NPs is also visible in Figure 1, particularly for the $3 \mathrm{~h}$ and $24 \mathrm{~h}$ samples. Similar carbon shells have been observed for $\mathrm{Cu}$ NPs produced by PLAL in acetone [28] and methanol [27].
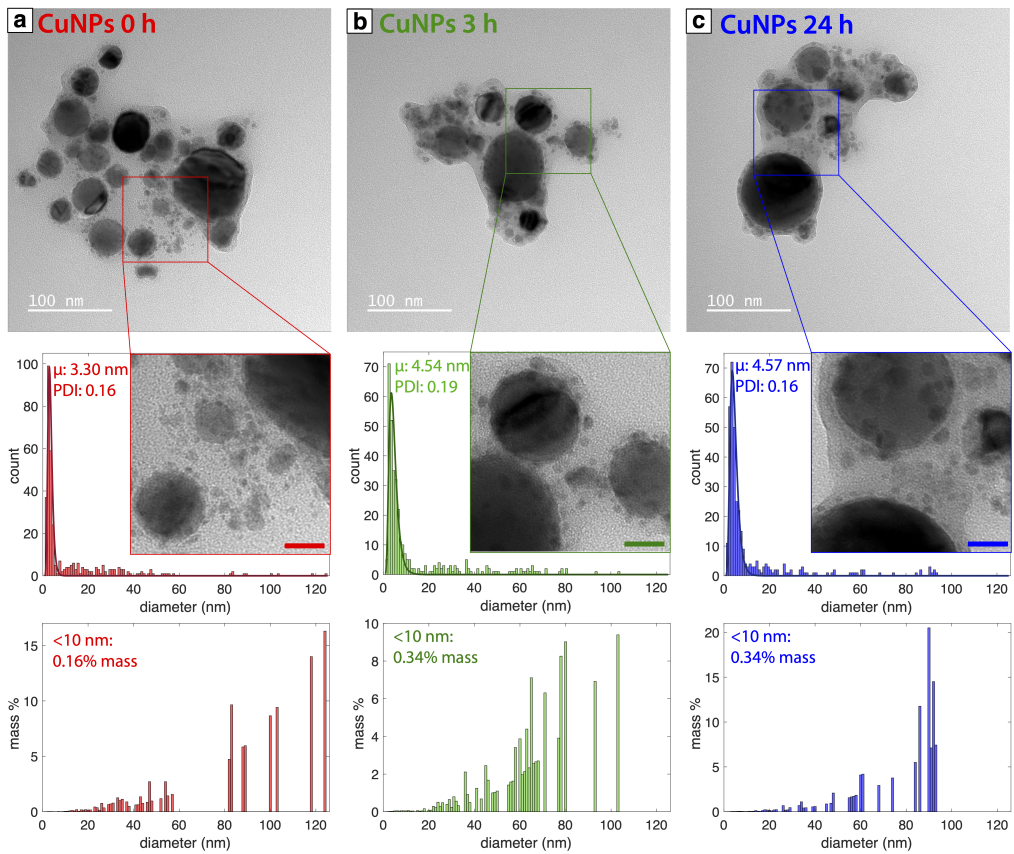

Figure 1. TEM images and corresponding number-weighted and mass-weighted size distributions for samples analyzed (a) $0 \mathrm{~h}$, (b) $3 \mathrm{~h}$, and (c) $24 \mathrm{~h}$ after synthesis. Scale bars in magnified regions are $20 \mathrm{~nm}$. 
Figure 2 shows the XRD spectrum of the $24 \mathrm{~h}$ sample. Intense diffraction peaks observed at $43.35^{\circ}, 50.47^{\circ}$, and $74.18^{\circ}$ were indexed to (111), (200), and (220) planes of fcc-Cu (JCPDS no. 01-085-1326), respectively. A broad feature centered at $36.85^{\circ}$ indexed to cubic- $\mathrm{Cu}_{2} \mathrm{O}(111)$ (JCPDS no. 00-005-0667) was also observed. Using the Scherrer equation, the crystallite sizes were calculated to be $29.89 \mathrm{~nm}$ for the $\mathrm{Cu}(111)$ [50]. Thus, we can infer that the large NPs observed in Figure 1 are $\mathrm{Cu}$ metal NPs, whereas $\mathrm{Cu}_{2} \mathrm{O}$ exists as an amorphous thin layer around the $\mathrm{Cu}$ NPs, as the smaller NPs, or both.

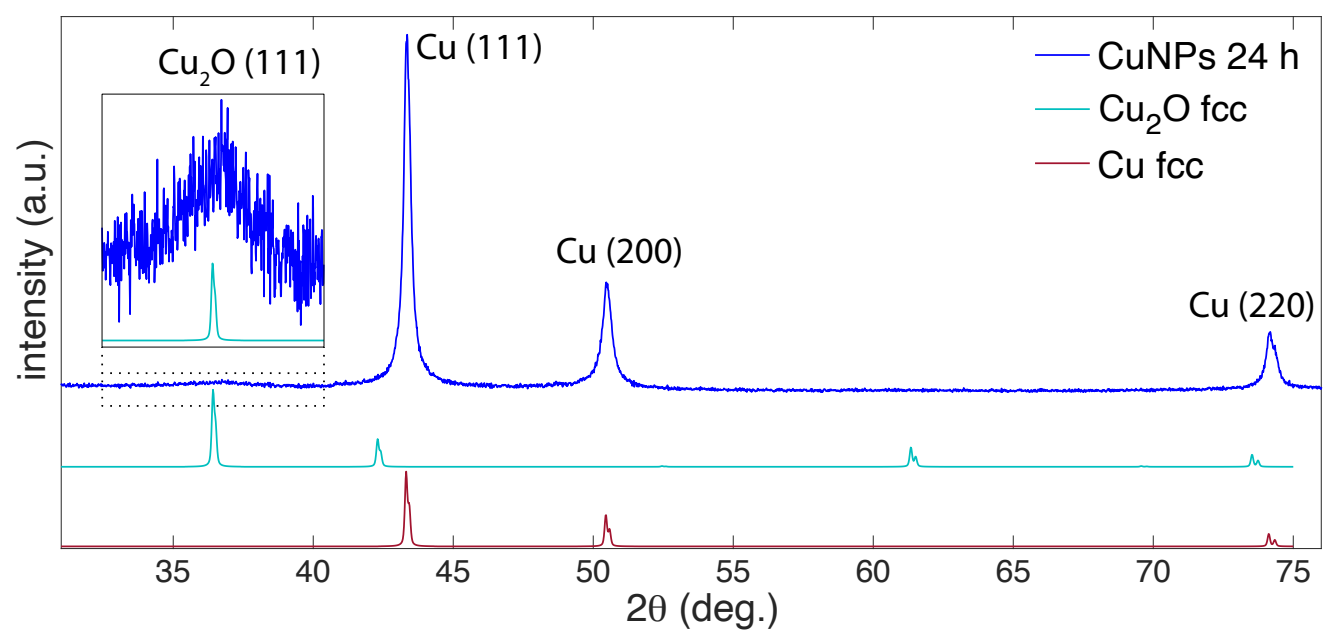

Figure 2. XRD spectrum of $24 \mathrm{~h}$ sample (blue), with references for $\mathrm{Cu}_{2} \mathrm{O}$ (cyan) and $\mathrm{Cu}$ (dark red). Inset magnifies a broad peak observed in the spectra for $24 \mathrm{~h}$ sample indexed to $\mathrm{Cu}_{2} \mathrm{O}(111)$.

Figure 3 shows XP spectra obtained for the $24 \mathrm{~h}$ sample. Two peaks in the $\mathrm{Cu} 2 \mathrm{p}_{3 / 2}$ region (Figure 3a) at $933.0 \mathrm{eV}$ (cyan) and $934.2 \mathrm{eV}$ (violet) were assigned to either $\mathrm{Cu}^{0}$ or $\mathrm{Cu}^{+}$and $\mathrm{Cu}^{2+}$, respectively [51]. To distinguish between $\mathrm{Cu}^{0}$ and $\mathrm{Cu}^{+}$, the CuLMM region was analyzed (Figure 3b) and resulted in two peaks at $568.4 \mathrm{eV}$ (blue) and $570.6 \mathrm{eV}$ (magenta) assigned to $\mathrm{Cu}^{0}$ and $\mathrm{Cu}^{+}$, respectively [51]. The presence of both $\mathrm{Cu}^{0}$ and $\mathrm{Cu}^{+}$ in the XP spectra is consistent with the XRD results (Figure 2). In the O1s region (Figure 3c), the peaks at $530.8 \mathrm{eV}$ (magenta), $531.7 \mathrm{eV}$ (light blue), $532.2 \mathrm{eV}$ (light green), and $533.0 \mathrm{eV}$ (dark green) were assigned to $\mathrm{Cu}-\mathrm{O}, \mathrm{C}=\mathrm{O},-\mathrm{OH}$ and $\mathrm{C}-\mathrm{O}$ species, respectively [52,53]. In the $\mathrm{C} 1 \mathrm{~s}$ region (Figure 3d), peaks at $284.4 \mathrm{eV}$ (red), $284.8 \mathrm{eV}$ (orange), $286.1 \mathrm{eV}$ (dark green), and $288.4 \mathrm{eV}$ (light blue) are assigned to $\mathrm{C}=\mathrm{C}, \mathrm{C}-\mathrm{C}, \mathrm{C}-\mathrm{O}$, and $\mathrm{C}=\mathrm{O}$ species, respectively [53]. This collection of carbon species is associated with the carbon shell observed around the $\mathrm{Cu}$ NPs (Figure 1).
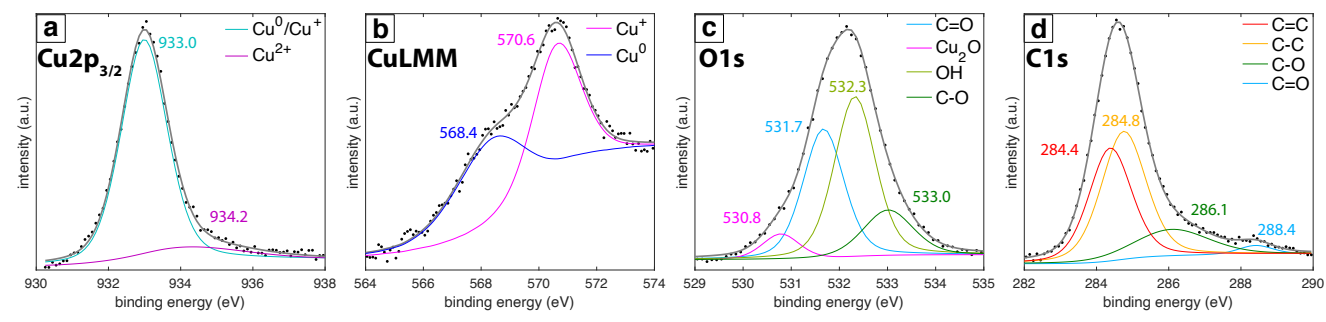

Figure 3. XPS spectra of (a) Cu2 $\mathrm{p}_{3 / 2}$, (b) CuLMM, (c) O1s and (d) C1s regions with fitted peaks for 24 h samples.

Spectral characterization of the $\mathrm{Cu}$ NPs (Figure 4) confirms the chemical species assigned in Figures 2 and 3. Figure 4a shows the UV-vis absorbance data collected at $0 \mathrm{~h}$, $3 \mathrm{~h}$, and $24 \mathrm{~h}$ after synthesis. An absorbance peak at $574 \mathrm{~nm}$ assigned to the $\mathrm{Cu}$ surface plasmon resonance (SPR) was observed at $0 \mathrm{~h}$, followed by broadening and red-shifting to $586 \mathrm{~nm}$ and $596 \mathrm{~nm}$ at $3 \mathrm{~h}$ and $24 \mathrm{~h}$, respectively. These changes in the absorbance peaks are associated with the oxidation of $\mathrm{Cu}$ to $\mathrm{Cu}_{2} \mathrm{O}$ over time [54] and likely indicate the formation 
of a $\mathrm{Cu}_{2} \mathrm{O}$ shell around the large $\mathrm{Cu}$ NPs on the basis of the XRD spectrum (Figure 2). Raman spectra shown in Figure $4 \mathrm{~b}$ closely resemble graphite oxide spectra [55]. The intense $\mathrm{G}$ band at $1600 \mathrm{~cm}^{-1}$ and $\mathrm{D}$ band at $1350 \mathrm{~cm}^{-1}$ correspond to the in-plane vibrational modes of $\mathrm{sp}^{2}$-hybridized carbon atoms and structural disorder due to functionalization, respectively [56]. Moreover, the weak and broad 2D and D + G bands at $2680 \mathrm{~cm}^{-1}$ and $2910 \mathrm{~cm}^{-1}$ arise from disorder due to formation of oxygen functional groups [55]. The presence of oxygen functional groups is confirmed by the FTIR spectra (Figure 4c) with peaks indicating $\mathrm{C}=\mathrm{O}$ stretch of $\mathrm{COOH}$ groups at 1722 and $1696 \mathrm{~cm}^{-1}, \mathrm{COO}^{-}$ stretch at 1415, 1522, $1575 \mathrm{~cm}^{-1}, \mathrm{O}-\mathrm{H}$ deformations of $\mathrm{C}-\mathrm{OH}$ groups at $1356 \mathrm{~cm}^{-1}, \mathrm{C}-\mathrm{O}$ stretch of epoxide groups at $1261 \mathrm{~cm}^{-1}, \mathrm{C}-\mathrm{O}$ stretch at $1000-1100 \mathrm{~cm}^{-1}$, and $\mathrm{C}-\mathrm{H}$ bend at $800 \mathrm{~cm}^{-1}$ [56,57], although some of these bands may be overlapped with vibrational modes of other functional groups. Notably, these IR peaks grow in intensity over the course of $24 \mathrm{~h}$ after synthesis, suggesting that the carbon shell formation occurs mostly after laser irradiation is terminated. Overall, these data and the XP spectra for C1s and O1s (Figure 3a,b) indicate that the carbon shell around the Cu NPs consists of disordered graphite oxide-like structures that contain multiple different functional groups.
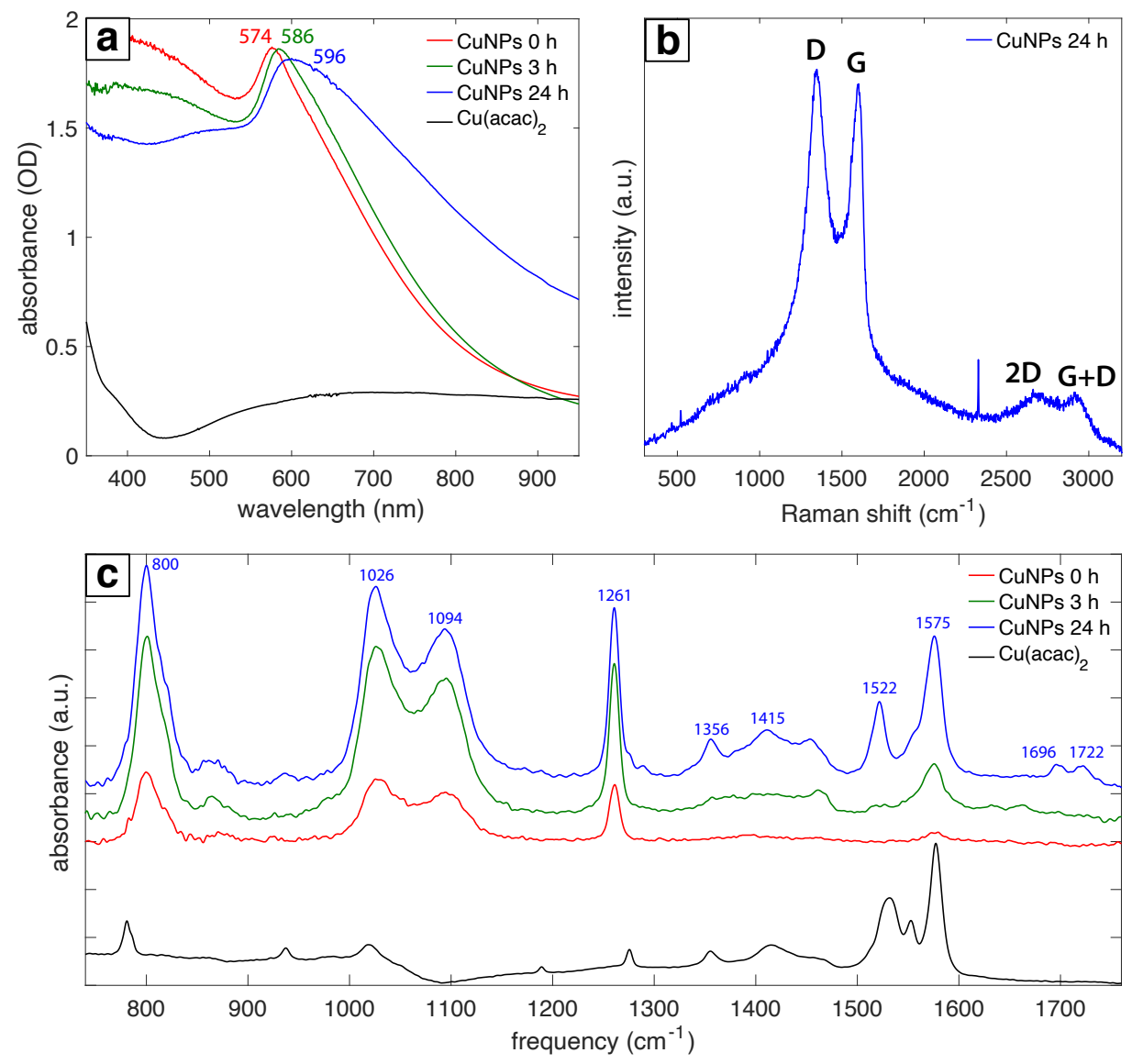

Figure 4. (a) UV-vis absorbance spectra for $0 \mathrm{~h}, 3 \mathrm{~h}, 24 \mathrm{~h}$ samples and precursor. (b) Raman spectra for $24 \mathrm{~h}$ samples. (c) FTIR spectra for $0 \mathrm{~h}, 3 \mathrm{~h}, 24 \mathrm{~h}$ samples and precursor.

\subsection{Catalytic Activity of $\mathrm{Cu}$ NPs}

Reduction of $\mathrm{PNP}$ by $\mathrm{NaBH}_{4}$ is a commonly used model reaction to test catalytic activity of metal NPs by employing UV-vis spectroscopy to monitor the decrease in absorbance of the $p$-nitrophenolate ion at $400 \mathrm{~nm}$, which allows for convenient determination of pseudo-first-order rate constants when excess $\mathrm{NaBH}_{4}$ is present $[58,59]$. Figure 5 a shows representative kinetic curves obtained from the ratio of the natural $\log$ of the $400 \mathrm{~nm}$ absorbance feature at time $t, \mathrm{~A}(t)$, to the initial absorbance, $\mathrm{A}(0)$, as a function of reaction time $t$ for the $0 \mathrm{~h}, 3 \mathrm{~h}$, and $24 \mathrm{~h}$ samples. The slopes obtained from the linear regions of the 
curves (shown in black) give the apparent rate constants $\left(k_{\mathrm{app}}\right)$. The values of $k_{\text {app }}$ were averaged over three different samples for all three post-synthesis times and then converted to the mass-specific rate constants $(k)$ of 1084,1479 , and $1927 \mathrm{~s}^{-1} \mathrm{~g}^{-1}$ for $0 \mathrm{~h}, 3 \mathrm{~h}$, and $24 \mathrm{~h}$ samples (Figure 5b). The specific rate at $3 \mathrm{~h}$ is comparable to the rate of $1490 \mathrm{~s}^{-1} \mathrm{~g}^{-1}$ for $\mathrm{Cu}$ NPs synthesized by PLAL in a water-ethanol mixture [30]. Although the rate constant is higher at $24 \mathrm{~h}$, this increase could be due to some evaporation of the solvent over time, resulting in concentration of the $\mathrm{Cu}$ NPs and an artificially high measured rate.
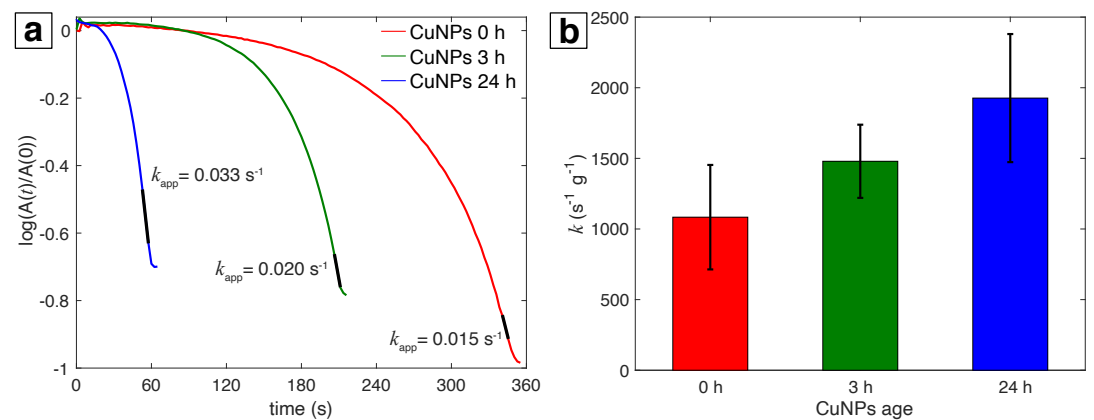

Figure 5. (a) Time dependence of the absorbance of $p$-nitrophenolate ions at $400 \mathrm{~nm}$ for a representative sample at $0 \mathrm{~h}, 3 \mathrm{~h}$, and $24 \mathrm{~h}$; black portion of line is where $\mathrm{k}_{a p p}\left(\mathrm{~s}^{-1}\right)$ is extracted. (b) Specific rate constants $\left(\mathrm{s}^{-1} \mathrm{~g}^{-1}\right)$ with error bars generated over three runs for $0 \mathrm{~h}, 3 \mathrm{~h}, 24 \mathrm{~h}$ samples each.

\subsection{Stability of $\mathrm{Cu} N \mathrm{NS}_{\mathrm{s}}$}

Figure 6 compares the UV-vis absorbance, XRD spectrum, and PNP kinetics for 1 day ( $24 \mathrm{~h}$ ) and 7 day samples. The Cu SPR peak observed for 7 day sample was only slightly red shifted compared to 1 day sample (Figure 6a), indicating no significant oxidation of $\mathrm{Cu}$ NPs. No changes were observed in the XRD peaks for 7 day samples (Figure $6 \mathrm{~b}$ ) compared 1 day samples (Figure 2), further confirming no or insignificant oxidation of $\mathrm{Cu}$ NPs. Accordingly, similar rate constants were obtained for 1 and 7 day samples for the PNP reduction reaction (Figure 6c). Collectively, these data indicate that the LRL Cu NPs are highly stable to oxidation.
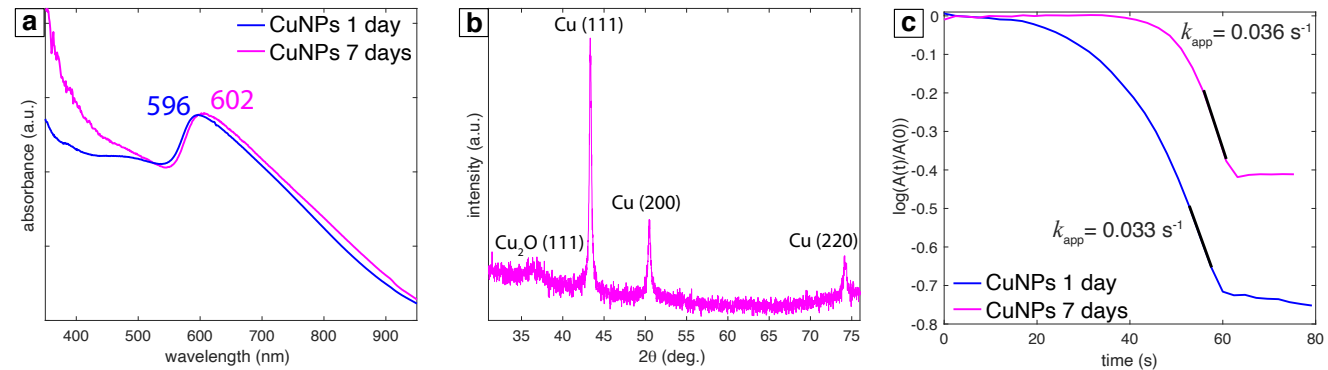

Figure 6. (a) UV-vis absorbance spectra measured at 1 day (blue) and 7 days (magenta). (b) XRD spectra for 7 day sample. (c) Time dependence of the absorbance of $p$-nitrophenolate ions at $400 \mathrm{~nm}$ for 1 day (blue) and 7 days (bright pink) samples; black portion of line is where $k_{\text {app }}\left(\mathrm{s}^{-1}\right)$ is extracted.

\section{Discussion}

The production of $\mathrm{Cu}$ metal NPs using LRL requires both an organic solvent and air-free conditions, as no laser-induced conversion of $\mathrm{Cu}(\mathrm{acac})_{2}$ precursor was observed when the solvent was water or when the precursor in IPA/methanol mixture was irradiated under ambient conditions. This result underscores the importance of minimizing reactive oxygen species formation during LRL, which was also needed to effectively control the sizes of Au NPs [35] and enable formation of Ag-containing NPs [41,44,45]. The important role of reactive oxygen species has also been noted in PLAL synthesis of Cu NPs, where air removal completely eliminated formation of the highly oxidized $\mathrm{CuO}$ phase during PLAL in water [28]. Collectively, these results highlight similarities in the chemical reaction 
pathways induced during both PLAL and LRL that can lead to metal NP oxidation, as well as the potential for the same strategies to mitigate oxide formation.

The formation of substantial quantities of sub-10 nm Cu NPs in our LRL synthesis is similar to previous LRL results for Au and Ag NPs using well-controlled solvent chemistry $[35,45]$, whereas the large $\mathrm{Cu}$ NPs up to $\sim 100 \mathrm{~nm}$ in diameter resemble the large Fe oxide NPs obtained from LRL of ferrocene in hexane [46]. The formation of two distinct size distributions of $\mathrm{Cu}$ NPs strongly suggests the participation of two different reaction mechanisms [33], although specific identification of these mechanisms is beyond the scope of this work. Nevertheless, on the basis of the PLAL literature demonstrating that substantial control over $\mathrm{Cu}$ NP size and morphology can be achieved by changing solvent mixtures [27-30], we anticipate that further exploration of different solvents will enable better control over $\mathrm{Cu}$ NP sizes using LRL. Finally, we note that the catalytic activity of the LRL Cu NPs to PNP reduction is comparable to that reported for PLAL Cu NPs [30], despite the presence of a thick carbon shell around our NPs. This result indicates that the carbon shell is sufficiently permeable to allow for catalytic reactions to take place and suggests that our LRL Cu NPs may have additional catalytic applications in areas, such as $\mathrm{CO}_{2}$ reduction or cross-coupling.

The formation of a substantial carbon shell around the LRL Cu NPs after termination of laser irradiation strongly suggests that the carbon formation is not entirely attributable to direct laser-induced solvent decomposition, as with PLAL in organic solvents $[16,17,27,28]$. Moreover, the lack of carbon shell formation during LRL of $\mathrm{Fe}(\mathrm{acac})_{3}$ in water [47] indicates that the acetylacetonate ligands from the precursor are not sufficient to induce carbon shell formation in LRL. On the basis of these results, we can speculate that the carbon shell is formed from catalytic activation on the $\mathrm{Cu}$ NP metal surfaces of long-lived solvent and ligand byproducts produced during laser irradiation. Cu metal is known to be a highly active catalyst in carbon-carbon cross-coupling reactions [19] and induces graphene growth from aliphatic alcohols under low-temperature CVD conditions [60]. Hence, we anticipate that the active bare $\mathrm{Cu}$ surfaces present immediately following laser irradiation catalyze the formation of the carbon shell. Although carbon shells are widely known to effectively protect transition metal NPs from oxidation [61-63], the evident permeability of the carbon around the LRL Cu NPs on the basis of their high catalytic activity suggests that a thin $\mathrm{Cu}_{2} \mathrm{O}$ layer around the $\mathrm{Cu}$ NPs also contributes to their observed stability [61].

\section{Conclusions}

We have reported the first synthesis of air-stable $\mathrm{Cu}$ NPs using the laser reduction in liquid (LRL) approach. Both small $(<10 \mathrm{~nm}$ ) and large (up to $100 \mathrm{~nm}$ ) spherical NPs were observed, which primarily consisted of $\mathrm{Cu}^{0}$ metal on the basis of XRD and XPS analysis, although a $\mathrm{Cu}_{2} \mathrm{O}$ shell around the large NPs may be present. The $\mathrm{Cu}$ NPs exhibit remarkable stability over 7 days on the basis of the lack of significant changes observed in the UV-vis absorbance and XRD features and the similar rate constants obtained for PNP reduction. The LRL Cu NPs compare favorably with PLAL-synthesized Cu NPs in terms of $\mathrm{Cu}^{0}$ content, stability, and catalytic activity. The insights into LRL of $\mathrm{Cu}^{2+}$ gained in this manuscript can be extended to other metals for which oxidation of NPs is commonly observed during PLAL or LRL. Finally, further development of the synthesis conditions, such as conducting LRL in a flow setup, could increase $\mathrm{Cu}$ NPs yield to produce heterogeneous catalysts for applications, such as cross-coupling reactions and $\mathrm{CO}_{2}$ reduction.

Author Contributions: K.M.T. and A.N. designed the research. A.N. performed the experiments and analyzed the data. L.M.F.B. performed experiments and processed the TEM data. A.N. and K.M.T. wrote the manuscript. All authors have read and agreed to the published version of the manuscript.

Funding: This work was supported by the American Chemical Society Petroleum Research Fund through Grant 57799-DNI10. L.M.F.B. acknowledges generous financial support from an Altria Graduate Research Fellowship. 
Institutional Review Board Statement: Not applicable.

Informed Consent Statement: Not applicable.

Data Availability Statement: Data presented in this study are available on request from the corresponding author.

Acknowledgments: Microscopy was performed at the VCU Department of Anatomy and Neurobiology Microscopy Facility, supported by the Higher Education Equipment Trust Fund Grant No. 236160307. We would like to acknowledge the VCU Nanomaterials Core Characterization Facility and Chemistry Instrumentation Facility for additional characterization.

Conflicts of Interest: The authors declare no conflict of interest.

\section{References}

1. Zhang, D.; Gökce, B.; Barcikowski, S. Laser Synthesis and Processing of Colloids: Fundamentals and Applications. Chem. Rev. 2017, 117, 3990-4103. [CrossRef] [PubMed]

2. Reichenberger, S.; Marzun, G.; Muhler, M.; Barcikowski, S. Perspective of Surfactant-free Colloidal Nanoparticles in Heterogeneous Catalysis. ChemCatChem 2019, 11, 4489-4518. [CrossRef]

3. Amans, D.; Cai, W.; Barcikowski, S. Status and demand of research to bring laser generation of nanoparticles in liquids to maturity. Appl. Surf. Sci. 2019, 488, 445-454. [CrossRef]

4. Swiatkowska-Warkocka, Z.; Pyatenko, A.; Krok, F.; Jany, B.R.; Marszalek, M. Synthesis of new metastable nanoalloys of immiscible metals with a pulse laser technique. Sci. Rep. 2015, 5, 9849. [CrossRef]

5. Tangeysh, B.; Odhner, J.H.; Wang, Y.; Wayland, B.B.; Levis, R.J. Formation of Copper(I) Oxide- and Copper(I) CyanidePolyacetonitrile Nanocomposites through Strong-Field Laser Processing of Acetonitrile Solutions of Copper(II) Acetate Dimer. J. Phys. Chem. A 2019, 123, 6430-6438. [CrossRef]

6. Streubel, R.; Barcikowski, S.; Gökce, B. Continuous multigram nanoparticle synthesis by high-power, high-repetition-rate ultrafast laser ablation in liquids. Opt. Lett. 2016, 41, 1486-1489. [CrossRef]

7. Amendola, V.; Meneghetti, M. What controls the composition and the structure of nanomaterials generated by laser ablation in liquid solution? Phys. Chem. Chem. Phys. 2013, 15, 3027-3046. [CrossRef]

8. Mastrotto, F.; Caliceti, P.; Amendola, V.; Bersani, S.; Magnusson, J.P.; Meneghetti, M.; Mantovani, G.; Alexander, C.; Salmaso, S. Polymer control of ligand display on gold nanoparticles for multimodal switchable cell targeting. Chem. Commun. 2011, 47, 9846-9848. [CrossRef]

9. Li, S.; Zhang, J.; Kibria, M.G.; Mi, Z.; Chaker, M.; Ma, D.; Nechache, R.; Rosei, F. Remarkably enhanced photocatalytic activity of laser ablated $\mathrm{Au}$ nanoparticle decorated $\mathrm{BiFeO} 3$ nanowires under visible-light. Chem. Commun. 2013, 49, 5856-5858. [CrossRef]

10. Zhang, J.; Chen, G.; Chaker, M.; Rosei, F.; Ma, D. Gold nanoparticle decorated ceria nanotubes with significantly high catalytic activity for the reduction of nitrophenol and mechanism study. Appl. Catal. B-Environ. 2013, 132-133, 107-115. [CrossRef]

11. Blakemore, J.D.; Gray, H.B.; Winkler, J.R.; Müller, A.M. Co3O4 Nanoparticle Water-Oxidation Catalysts Made by Pulsed-Laser Ablation in Liquids. ACS Catal. 2013, 3, 2497-2500. [CrossRef]

12. Gu, S.; Kaiser, J.; Marzun, G.; Ott, A.; Lu, Y.; Ballauff, M.; Zaccone, A.; Barcikowski, S.; Wagener, P. Ligand-free Gold Nanoparticles as a Reference Material for Kinetic Modelling of Catalytic Reduction of 4-Nitrophenol. Catal. Lett. 2015, 145, 1105-1112. [CrossRef]

13. Longano, D.; Ditaranto, N.; Cioffi, N.; Di Niso, F.; Sibillano, T.; Ancona, A.; Conte, A.; Del Nobile, M.A.; Sabbatini, L.; Torsi, L. Analytical characterization of laser-generated copper nanoparticles for antibacterial composite food packaging. Anal. Bioanal. Chem. 2012, 403, 1179-1186. [CrossRef] [PubMed]

14. Naddeo, J.; Ratti, M.; O’Malley, S.; Griepenburg, J.; Bubb, D.; Klein, E. Antibacterial Properties of Nanoparticles: A Comparative Review of Chemically Synthesized and Laser-Generated Particles. Adv. Sci. Eng. Med. 2015, 7, 1044-1057. [CrossRef]

15. Petersen, S.; Barcikowski, S. In Situ Bioconjugation: Single Step Approach to Tailored Nanoparticle-Bioconjugates by Ultrashort Pulsed Laser Ablation. Adv. Funct. Mater. 2009, 19, 1167-1172. [CrossRef]

16. Zhang, H.; Liang, C.; Liu, J.; Tian, Z.; Shao, G. The formation of onion-like carbon-encapsulated cobalt carbide core/shell nanoparticles by the laser ablation of metallic cobalt in acetone. Carbon 2013, 55, 108-115. [CrossRef]

17. Yu-jin, K.; Ma, R.; Reddy, D.A.; Kim, T.K. Liquid-phase pulsed laser ablation synthesis of graphitized carbon-encapsulated palladium core-shell nanospheres for catalytic reduction of nitrobenzene to aniline. Appl. Surf. Sci. 2015, 357, 2112-2120. [CrossRef]

18. Kim, J.H.; Chung, Y.K. Copper nanoparticle-catalyzed cross-coupling of alkyl halides with Grignard reagents. Chem. Commun. 2013, 49, 11101-11103. [CrossRef] [PubMed]

19. Gawande, M.B.; Goswami, A.; Felpin, F.X.; Asefa, T.; Huang, X.; Silva, R.; Zou, X.; Zboril, R.; Varma, R.S. Cu and Cu-Based Nanoparticles: Synthesis and Applications in Catalysis. Chem. Rev. 2016, 116, 3722-3811. [CrossRef] [PubMed]

20. Kwon, Y.T.; Lee, Y.I.; Kim, S.; Lee, K.J.; Choa, Y.H. Full densification of inkjet-printed copper conductive tracks on a flexible substrate utilizing a hydrogen plasma sintering. Appl. Surf. Sci. 2017, 396, 1239-1244. [CrossRef]

21. Pugazhendhi, A.; Edison, T.N.J.I.; Karuppusamy, I.; Kathirvel, B. Inorganic nanoparticles: A potential cancer therapy for human welfare. Int. J. Pharm. 2018, 539, 104-111. [CrossRef] 
22. Park, J.H.; Seo, J.; Kim, C.; Joe, D.J.; Lee, H.E.; Im, T.H.; Seok, J.Y.; Jeong, C.K.; Ma, B.S.; Park, H.K.; et al. Flash-Induced Stretchable Cu Conductor via Multiscale-Interfacial Couplings. Adv. Sci. 2018, 5, 1801146. [CrossRef]

23. Song, X.; Sun, S.; Zhang, W.; Yin, Z. A method for the synthesis of spherical copper nanoparticles in the organic phase. J. Colloid Interface Sci. 2004, 273, 463-469. [CrossRef]

24. Dharmadasa, R.; Jha, M.; Amos, D.A.; Druffel, T. Room Temperature Synthesis of a Copper Ink for the Intense Pulsed Light Sintering of Conductive Copper Films. ACS Appl. Mater. Interfaces 2013, 5, 13227-13234. PMID: 24283767. [CrossRef]

25. Mott, D.; Galkowski, J.; Wang, L.; Luo, J.; Zhong, C.J. Synthesis of Size-Controlled and Shaped Copper Nanoparticles. Langmuir 2007, 23, 5740-5745. PMID: 17407333. [CrossRef] [PubMed]

26. Swarnkar, R.K.; Singh, S.C.; Gopal, R. Effect of aging on copper nanoparticles synthesized by pulsed laser ablation in water: structural and optical characterizations. Bull. Mater. Sci. 2011, 34, 1363-1369. [CrossRef]

27. Fernández-Arias, M.; Boutinguiza, M.; Del Val, J.; Covarrubias, C.; Bastias, F.; Gómez, L.; Maureira, M.; Arias-González, F.; Riveiro, A.; Pou, J. Copper nanoparticles obtained by laser ablation in liquids as bactericidal agent for dental applications. Appl. Surf. Sci. 2020, 507, 145032. [CrossRef]

28. Marzun, G.; Levish, A.; Mackert, V.; Kallio, T.; Barcikowski, S.; Wagener, P. Laser synthesis, structure and chemical properties of colloidal nickel-molybdenum nanoparticles for the substitution of noble metals in heterogeneous catalysis. J. Colloid Interface Sci. 2017, 489, 57-67. [CrossRef] [PubMed]

29. Goncharova, D.A.; Kharlamova, T.S.; Lapin, I.N.; Svetlichnyi, V.A. Chemical and Morphological Evolution of Copper Nanoparticles Obtained by Pulsed Laser Ablation in Liquid. J. Phys. Chem. C 2019, 123, 21731-21742. [CrossRef]

30. Goncharova, D.A.; Kharlamova, T.S.; Reutova, O.A.; Svetlichnyi, V.A. Water-ethanol CuOx nanoparticle colloids prepared by laser ablation: Colloid stability and catalytic properties in nitrophenol hydrogenation. Colloids Surf. A Physicochem. Eng. Asp. 2021, 613, 126115. [CrossRef]

31. Rehbock, C.; Merk, V.; Gamrad, L.; Streubel, R.; Barcikowski, S. Size Control of Laser-Fabricated Surfactant-Free Gold Nanoparticles with Highly Diluted Electrolytes and their Subsequent Bioconjugation. Phys. Chem. Chem. Phys. 2013, 15, 3057-3067. [CrossRef]

32. Sylvestre, J.P.; Kabashin, A.V.; Sacher, E.; Meunier, M. Femtosecond laser ablation of gold in water: influence of the laser-produced plasma on the nanoparticle size distribution. Appl. Phys. A 2005, 80,753-758. [CrossRef]

33. Shih, C.Y.; Streubel, R.; Heberle, J.; Letzel, A.; Shugaev, M.V.; Wu, C.; Schmidt, M.; Gökce, B.; Barcikowski, S.; Zhigilei, L.V. Two mechanisms of nanoparticle generation in picosecond laser ablation in liquids: the origin of the bimodal size distribution. Nanoscale 2018, 10, 6900-6910. [CrossRef]

34. Rodrigues, C.J.; Bobb, J.A.; John, M.G.; Fisenko, S.P.; El-Shall, M.S.; Tibbetts, K.M. Nucleation and growth of gold nanoparticles initiated by nanosecond and femtosecond laser irradiation of aqueous [AuCl4]-. Phys. Chem. Chem. Phys. 2018, 20, 28465-28475. [CrossRef]

35. Frias Batista, L.M.; Meader, V.K.; Romero, K.; Kunzler, K.; Kabir, F.; Bullock, A.; Tibbetts, K.M. Kinetic Control of [AuCl $]_{4}^{-}$ Photochemical Reduction and Gold Nanoparticle Size with Hydroxyl Radical Scavengers. J. Phys.Chem. B 2019, 123, 7204-7213. [CrossRef] [PubMed]

36. Nakamura, T.; Mochidzuki, Y.; Sato, S. Fabrication of Gold Nanoparticles in Intense Optical Field by Femtosecond Laser Irradiation of Aqueous Solution. J. Mater. Res. 2008, 23, 968-974. [CrossRef]

37. Tangeysh, B.; Moore Tibbetts, K.; Odhner, J.H.; Wayland, B.B.; Levis, R.J. Gold Nanoparticle Synthesis Using Spatially and Temporally Shaped Femtosecond Laser Pulses: Post-Irradiation Auto-Reduction of Aqueous $\left[\mathrm{AuCl}_{4}\right]^{-}$. J. Phys. Chem. C 2013, 117, 18719-18727. [CrossRef]

38. Meader, V.K.; John, M.G.; Rodrigues, C.J.; Tibbetts, K.M. Roles of Free Electrons and H2O2 in the Optical Breakdown-Induced Photochemical Reduction of Aqueous [AuCl4]-. J. Phys. Chem. A 2017, 121, 6742-6754. [CrossRef] [PubMed]

39. Nakamura, T.; Magara, H.; Herbani, Y.; Sato, S. Fabrication of silver nanoparticles by highly intense laser irradiation of aqueous solution. Appl. Phys. A 2011, 104, 1021. [CrossRef]

40. Herbani, Y.; Nakamura, T.; Sato, S. Silver nanoparticle formation by femtosecond laser induced reduction of ammonia-containing AgNO 3 solution. J. Phys. Conf. Ser. 2017, 817, 012048. [CrossRef]

41. Meader, V.K.; John, M.G.; Frias Batista, L.M.; Ahsan, S.; Tibbetts, K.M. Radical Chemistry in a Femtosecond Laser Plasma: Photochemical Reduction of $\mathrm{Ag}^{+}$in Liquid Ammonia Solution. Molecules 2018, 23, 532. [CrossRef]

42. Nakamura, T.; Takasaki, K.; Ito, A.; Sato, S. Fabrication of platinum particles by intense, femtosecond laser pulse irradiation of aqueous solution. Appl. Surf. Sci. 2009, 255, 9630-9633. [CrossRef]

43. Herbani, Y.; Nakamura, T.; Sato, S. Synthesis of platinum-based binary and ternary alloy nanoparticles in an intense laser field. J. Colloid Interface Sci. 2012, 375, 78-87. [CrossRef]

44. Herbani, Y.; Nakamura, T.; Sato, S. Spectroscopic monitoring on irradiation-induced formation of AuAg alloy nanoparticles by femtosecond laser. In AIP Conference Proceedings; AIP Publishing LLC: Melville, NY, USA, 2016; Volume 1711, p. 030005. [CrossRef]

45. Nguyen, C.M.; Frias Batista, L.M.; John, M.G.; Rodrigues, C.J.; Tibbetts, K.M. Mechanism of Gold-Silver Alloy Nanoparticle Formation by Laser Coreduction of Gold and Silver Ions in Solution. J. Phys. Chem. B 2021, 125, 907-917. PMID: 33439650. [CrossRef] 
46. Okamoto, T.; Nakamura, T.; Kihara, R.; Asahi, T.; Sakota, K.; Yatsuhashi, T. Synthesis of Bare Iron Nanoparticles from Ferrocene Hexane Solution by Femtosecond Laser Pulses. ChemPhysChem 2018, 19, 2480-2485. [CrossRef]

47. Okamoto, T.; Nakamura, T.; Tahara, Y.O.; Miyata, M.; Sakota, K.; Yatsuhashi, T. Effects of Ligand and Solvent on the Synthesis of Iron Oxide Nanoparticles from Fe(acac)3 Solution by Femtosecond Laser Irradiation. Chem. Lett. 2020, 49, 75-78. [CrossRef]

48. Dhas, N.A.; Raj, C.P.; Gedanken, A. Synthesis, Characterization, and Properties of Metallic Copper Nanoparticles. Chem. Mater. 1998, 10, 1446-1452. [CrossRef]

49. John, M.G.; Tibbetts, K.M. One-step femtosecond laser ablation synthesis of sub-3 nm gold nanoparticles stabilized by silica. Appl. Surf. Sci. 2019, 475, 1048-1057. [CrossRef]

50. Holzwarth, U.; Gibson, N. The Scherrer equation versus the 'Debye-Scherrer equation'. Nat. Nanotechnol. 2011, 6, 534. [CrossRef] [PubMed]

51. Ghodselahi, T.; Vesaghi, M.; Shafiekhani, A.; Baghizadeh, A.; Lameii, M. XPS study of the Cu@Cu2O core-shell nanoparticles. Appl. Surf. Sci. 2008, 255, 2730-2734. [CrossRef]

52. Wagner, C.; M, R.W.; Davis, L.E.; Moulder, J.F.; Muilenburg, G.E. Handbook of X-ray Photoelectron Spectroscopy; Physical Electronics Division; Perkin-Elmer Corp.: Maharashtra, India, 1979.

53. Yu, B.; Wang, X.; Qian, X.; Xing, W.; Yang, H.; Ma, L.; Lin, Y.; Jiang, S.; Song, L.; Hu, Y.; et al. Functionalized graphene oxide/phosphoramide oligomer hybrids flame retardant prepared via in situ polymerization for improving the fire safety of polypropylene. RSC Adv. 2014, 4, 31782-31794. [CrossRef]

54. Rice, K.P.; Walker, E.J.; Stoykovich, M.P.; Saunders, A.E. Solvent-Dependent Surface Plasmon Response and Oxidation of Copper Nanocrystals. J. Phys. Chem. C 2011, 115, 1793-1799. [CrossRef]

55. Tiwari, S.K.; Hatui, G.; Oraon, R.; De Adhikari, A.; Nayak, G.C. Mixing sequence driven controlled dispersion of graphene oxide in PC/PMMA blend nanocomposite and its effect on thermo-mechanical properties. Curr. Appl. Phys. 2017, 17, 1158-1168. [CrossRef]

56. Bobb, J.A.; Rodrigues, C.J.; El-Shall, M.S.; Tibbetts, K.M. Laser-assisted synthesis of gold-graphene oxide nanocomposites: effect of pulse duration. Phys. Chem. Chem. Phys. 2020, 22, 18294-18303. [CrossRef] [PubMed]

57. Baharuddin, A.A.; Ang, B.C.; Wong, Y.H. Self-assembly and electrical characteristics of 4-pentynoic acid functionalized Fe3O4- $\gamma$ Fe2O3 nanoparticles on SiO2/n-Si. Appl. Surf. Sci. 2017, 423, 236-244. [CrossRef]

58. Wunder, S.; Polzer, F.; Lu, Y.; Mei, Y.; Ballauff, M. Kinetic Analysis of Catalytic Reduction of 4-Nitrophenol by Metallic Nanoparticles Immobilized in Spherical Polyelectrolyte Brushes. J. Phys. Chem. C 2010, 114, 8814-8820. [CrossRef]

59. Aditya, T.; Pal, A.; Pal, T. Nitroarene reduction: a trusted model reaction to test nanoparticle catalysts. Chem. Commun. 2015, 51, 9410-9431. [CrossRef] [PubMed]

60. Guermoune, A.; Chari, T.; Popescu, F.; Sabri, S.S.; Guillemette, J.; Skulason, H.S.; Szkopek, T.; Siaj, M. Chemical vapor deposition synthesis of graphene on copper with methanol, ethanol, and propanol precursors. Carbon 2011, 49, 4204-4210. [CrossRef]

61. Galaburda, M.; Kovalska, E.; Hogan, B.T.; Baldycheva, A.; Nikolenko, A.; Dovbeshko, G.I.; Oranska, O.I.; Bogatyrov, V.M. Mechanochemical synthesis of carbon-stabilized $\mathrm{Cu} / \mathrm{C}, \mathrm{Co} / \mathrm{C}$ and $\mathrm{Ni} / \mathrm{C}$ nanocomposites with prolonged resistance to oxidation. Sci. Rep. 2019, 9, 17435. [CrossRef]

62. Stein, M.; Wieland, J.; Steurer, P.; Tölle, F.; Mülhaupt, R.; Breit, B. Iron Nanoparticles Supported on Chemically-Derived Graphene: Catalytic Hydrogenation with Magnetic Catalyst Separation. Adv. Syn. Catal. 2011, 353, 523-527. [CrossRef]

63. Tsang, S.C.; Caps, V.; Paraskevas, I.; Chadwick, D.; Thompsett, D. Magnetically Separable, Carbon-Supported Nanocatalysts for the Manufacture of Fine Chemicals. Angew. Chem. Int. Ed. 2004, 43, 5645-5649. [CrossRef] [PubMed] 